\title{
Características morfológicas da confluência dos rios Negro e Solimões (Amazonas, Brasil)
}

\author{
Elena Franzinelli ${ }^{1}$
}

\begin{abstract}
Resumo A confluência dos rios Negro e Solimões, que origina o Rio Amazonas, está situada na faixa da neotectônica transcorrente que se estende de leste para oeste na parte central da Bacia do Amazonas. Nessa área, os depósitos clásticos da Formação Alter do Chão, de idade cretácea, formam o assoalho dos sedimentos fluviais recentes. Na confluência, o Rio Negro apresenta largura de $3 \mathrm{~km}$ e profundidade de $90 \mathrm{~m}$. Seu ultimo trecho é definido pela neotectônica e é escavado nos depósitos da Formação Alter do Chão que formam a sua margem norte continuando ao leste na margem norte do Rio Amazonas. O Rio Solimões, na confluência, apresenta largura de $2 \mathrm{~km}$ e profundidade de $35 \mathrm{~m}$.O ângulo do encontro dos rios é definido pela neotectônica. No interflúvio, a Ilha Xiborena é constituída de sedimentos recentes dispostos em bancos alongados, recurvados. A correlação de perfis batimétricos, obtidos de dados de cartas náuticas da Marinha do Brasil (1978, 1988, 1998), mostra que a Ponta do Catalão, extremidade leste da Ilha Xiborena, teve aumento da superfície e mudança da forma durante esse período e permite verificar as mudanças ocorridas no leito do Rio Amazonas por efeito da erosão e deposição. Nota-se a considerável modificação na localização e na profundidade do sulco de lavagem (scour), a irregularidade do leito do Amazonas em seu trecho inicial, a deposição de sedimentos na margem direita, a formação de barras longitudinais no centro do canal, a $15 \mathrm{~km}$ da confluência.
\end{abstract}

Palavras-chave: Encontro das águas, Rio Amazonas, Rio Solimões, Rio Negro.

\begin{abstract}
Morphological characteristics of the Negro and Solimões rivers confluence. The confluence of the Negro and Solimões rivers to originate the Amazonas is located in the transcurrent neotectonic belt which extends from east to west in the central part of the Amazon Basin. The last reach of the Negro River is defined by neotectonics, and it is carved in the Cretaceous rock of the Alter do Chão Formation which forms red cliffs on its north side that continue on the side of the Amazon after the confluence. The Negro River at the confluence is $3 \mathrm{~km}$ wide and $90 \mathrm{~m}$ deep. At this point the Solimões is $2 \mathrm{~km}$ wide and $35 \mathrm{~m}$ deep. The junction angle is also defined by neotectonics. The confluence flow separation bar, called Xiborena Island, is formed by long, curved banks of modern sediments. An analysis of nautical charts from three decades $(1978,1988,1998)$ and bathymetrical cross sections obtained from these charts permitted an examination of the morphology and an evaluation of the modification that have occurred in this period on the bed of the Amazonas due to erosion or deposition. The so called Ponta do Catalão, that is, the outer bar of Xiborena Island increased in surface area and changed in shape. The scour hole at the confluence changed in place and in depth from 34 to $43 \mathrm{~m}$, some long bars were formed by lateral accretion on the south side of the Amazon and some post-confluence midchannel bars were formed in the river $15 \mathrm{~km}$ up from Ponta do Catalão.
\end{abstract}

Keywords: Meeting of the Waters, Amazonas River, Solimões River, Negro River.

INTRODUÇÃO O Rio Amazonas, em território brasileiro, nasce no encontro das águas negras do Rio Negro e das águas brancas do Solimões, próximo à cidade de Manaus (Fig. 1). As nascentes do Solimões estão localizadas nos Andes e o Rio Negro, afluente da margem esquerda do Solimões, provém do Escudo das Guianas. Ambos possuem vastas bacias com características diferentes a respeito do relevo, climas e tipos de rochas que definem a qualidade de suas águas e as cargas sólidas. Ambos percorrem centenas de quilômetros antes de se encontrarem.

$\mathrm{Na}$ bibliografia são encontrados numerosos trabalhos com resultados de investigações dos Rios
Solimões e Negro, sendo que os mais significativos são: as observações precursoras de Bates (1864), os trabalhos pioneiros de Oltman (1967) sobre a descarga líquida, a identificação e quantificação dos sedimentos em suspensão por Gibbs (1967), a classificação dos sedimentos de fundo por Nordin et al. (1977) e Mertes \& Meade (1985), a identificação das areias das barras dos rios da Bacia Amazônica por Franzinelli \& Potter (1983), a origem da cor da água do Rio Negro por Sioli (1991), a origem das areias quartzosas do Rio Negro por Potter \& Franzinelli (1985), a influência da geologia e intemperismo para os sedimentos em solução do sistema Rio Negro por Stallard \& Edmond (1983), 


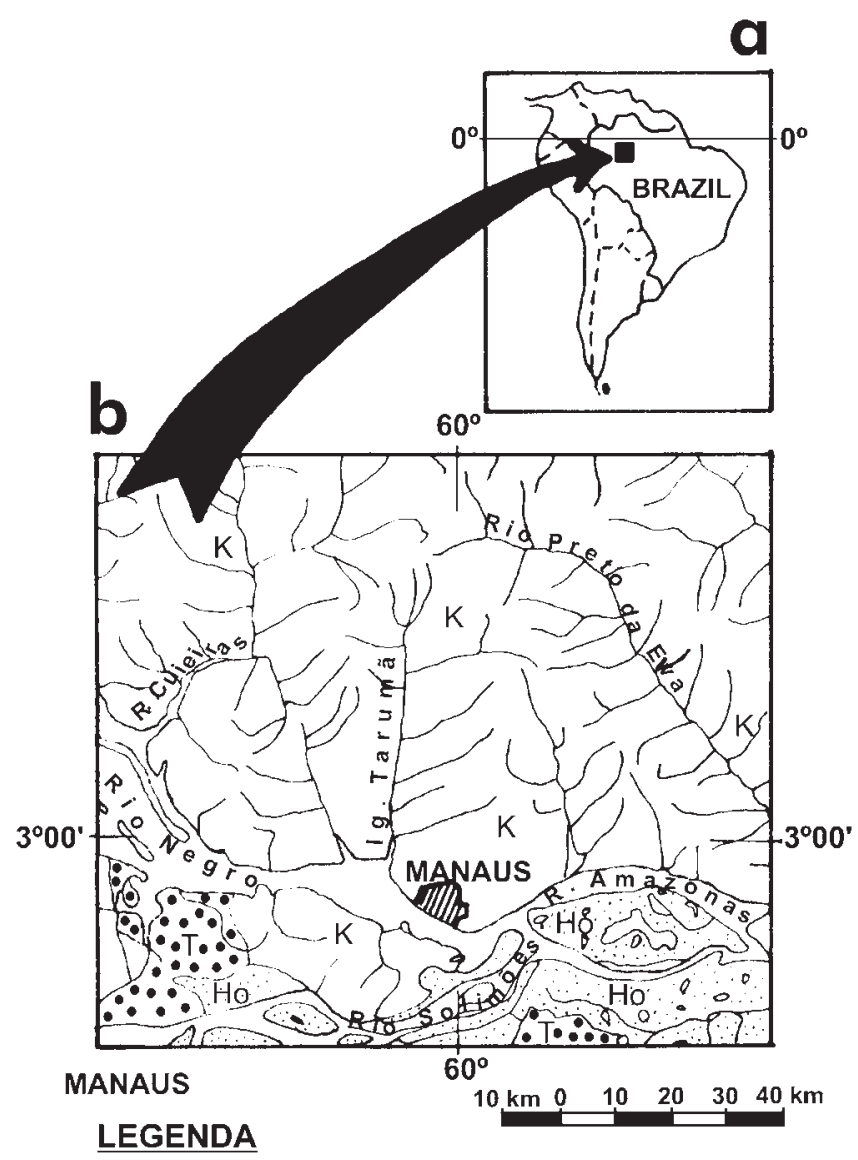

HiO DEPÓSITOS QUATERNÁRIOS

:T:: FORMAÇÃO SOLIMŌES

K FORMAÇÃO ALTER DO CHÃO

Figura 1 - a: Mapa de localização. b: Esboço geológico da região próxima a Manaus.

a neotectônica e a sedimentação no Baixo Rio Negro por Franzinelli \& Igreja (2002), e a evolução quaternária do Rio Negro por Latrubesse \& Franzinelli (2005). Todavia, não são conhecidos trabalhos que tratem dos fenômenos que ocorrem no encontro das águas dos Rios Solimões e Negro.

Entretanto, as confluências de rios são frequentes e constituem importantes elementos morfológicos em qualquer sistema fluvial: são locais nos quais ocorrem mudanças repentinas da vazão devido aos seguintes fatores: integração de dois fluxos diferentes; variações de concentração de sedimentos em suspensão e alteração da composição da carga de fundo. Em termos hidráulicos, as confluências constituem áreas susceptíveis a ocorrências de turbulências, com movimentos convergentes e divergentes, formações de vórtices ascendentes (upwellings), descendentes (downwellings) e horizontais (lateral vortex) (Morisawa 1968). As alterações das características de fluxo, junto com a movimentação da carga de fundo nos pontos da confluência, geralmente provocam transformações morfológicas no canal, com formações de cavidades similares a poços e deposição de sedimentos sob forma de barras. De acordo com Best (1988) e Bristow et al. (1993) a morfologia do canal na confluência de rios é caracterizada por três elementos distintos: uma queda rápida com aspecto de avalanche na superfície do leito na boca de cada tributário, uma profunda escavação central (scour) no ponto da confluência, e a formação de barras a jusante da confluência. Segundo os mesmos pesquisadores, esses elementos são controlados predominantemente pelo ângulo da confluência e a razão da descarga entre o canal principal e o tributário.

Existe uma quantidade relativamente grande de estudos de confluências disponíveis na literatura. Entretanto, tais estudos referem-se a cursos de água de pequeno porte ou se restringem a resultados de simulações em laboratórios. Segundo Parson et al. (2008), raras são as investigações detalhadas de fluxo, transporte de sedimentos e morfologia do leito de grandes rios e é discutível o fato de se poder aplicar os modelos obtidos em canais menores a rios mais largos, com canais de mais de $100 \mathrm{~m}$ de largura. Best \& Ashworth (1997) apresentam dados da morfologia da confluência dos rios Jaruma e Ganga, em Bangladesh. Segundo esses autores, algumas feições da morfologia do leito do canal resultante são semelhantes à morfologia de confluências menores, como o sulco de lavagem central (scour) e a acumulação de sedimentos a jusante do ângulo da união, formando barras centrais. Entretanto, há divergência a respeito da ocorrência e morfologia da avalanche na boca dos tributários. Também em pesquisas efetuadas em confluências de canais em extremidades de barras do Rio Paraná, tipo de rio anastomosado, foram obtidos resultados similares.

O presente trabalho propõe a investigação da morfologia do canal do Rio Amazonas na confluência dos rios Solimões e Negro e o estudo da evolução das formas do leito no período de 1978 a 1998.

MÉTODOS DO ESTUDO O estudo da morfologia do leito do Rio Amazonas foi baseado na utilização de dados batimétricos de cartas náuticas da Diretoria de Hidrografia e Navegação da Marinha dos anos 1978, 1988, 1998, atualizadas em períodos entre as cheias e as secas, quando as águas dos rios estavam no mesmo nível. Com o uso dessas cartas, foi possível traçar perfis batimétricos apropriados e efetuar correlações entre eles. O estudo prévio de materiais de sensoriamento remoto também foi importante: imagens de radar de escala 1:250.000, fotografias aéreas de escalas variáveis, imagens de satélite de diferentes escalas e imagens do Programa Google Earth (http://earth.google.com). Por fim, foram de grande utilidade as observações e dados levantados em trabalhos de campo, realizados nos anos precedentes, em áreas próximas ao Encontro das águas, ao longo das margens dos rios Solimões e Negro, na zona de interflúvio, na margem esquerda do Rio Amazonas e na Ilha do Careiro, com a finalidade de identificar os depósitos sedimentares ali existentes e as estruturas associadas. 
ASPECTOS GEOLÓGICOS DA ÁREA DA CONFLUÊNCIA Na região do encontro das águas dos rios Negro e Solimões, na parte central da Bacia do Amazonas (Fig. 1), afloram rochas clásticas da Formação Alter do Chão, do Cretáceo superior. São camadas espessas de argilas siltosas vermelhas, fortemente alteradas, com frequentes concreções lateríticas e bancos de arenitos argilosos, vermelhos ou esbranquiçados, localmente silicificados (Arenito Manaus, Albuquerque 1922).

A planície de inundação do rio Amazonas, nessa região, está assentada sobre a Formação Alter do Chão. Esta planície, de idade holocênica, é constituída de depósitos de areias líticas, finas, bem selecionadas, alternadas com leitos de argilas cinzentas. Até o momento, não é conhecida a espessura máxima desses depósitos que, em superfície são arranjados em formas variadas de feixes de barras fluviais de tipo restinga lineares ou recurvadas, derivadas de sucessivos depósitos de diques, ou de depósitos homogêneos de lenta colmatagem.

O Rio Solimões, ao longo do seu trajeto, corre, ora na planície por ele mesmo formada, ora entre a margem da planície e as rochas da Formação Alter do Chão. A margem direita do Rio Solimões, a montante do Encontro das águas, está situada na planície de inundação; a margem esquerda, na altura de Iranduba e ao oeste da Ilha Xiborena (Fig. 2) é formada por barrancos vermelhos da Formação Alter do Chão, compostos por bancos de arenitos grosseiros, alternados por camadas silte-argilosas. A jusante de Iranduba, o terraço da Formação Alter do Chão se afasta para deixar lugar à várzea. O baixo curso do Rio Negro está fortemente influenciado pela neotectônica. A montante do Encontro das águas, sua margem esquerda é limitada pelas "barreiras vermelhas" da Formação Alter do Chão que segue ao leste formando a margem esquerda do Rio Amazonas, onde, logo após o Encontro das águas forma terraço que alcança $90 \mathrm{~m}$ acima do nível do mar. Na base do terraço ocorre a Ponta das Lajes, onde as rochas silicificadas da Formação Alter do Chão se estendem por dezenas de metros para dentro do canal, sendo descobertas somente nas estações de seca. A jusante da Ponta das Lajes a Formação Alter do Chão recua para NE e a margem do Amazonas é formada por bancos tipo "restinga" de sedimentos modernos que limitam o Lago do Aleixo. A área de interflúvio, Ilha Xiborena, é constituída de feixes de bancos de sedimentos modernos, dispostos na direção $\mathrm{N}-\mathrm{S}$ encurvados para $\mathrm{W}$, definindo a direção do ângulo da confluência dos rios. As depressões entre os bancos são colmatadas; algumas ainda na fase de colmatagem possuem canal navegável durante as cheias (Paraná da Xiborena e Furo de Paracuuba).

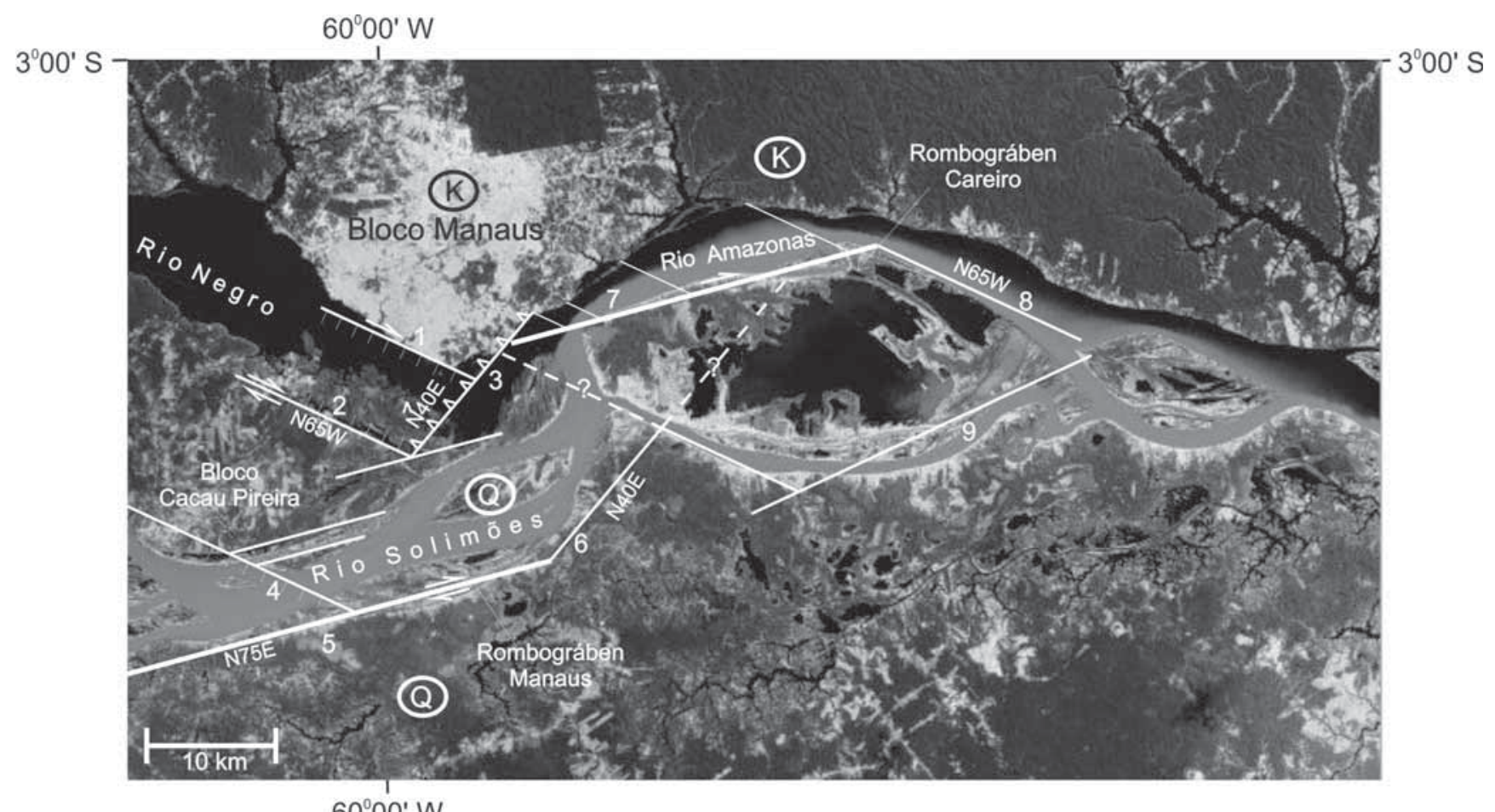

$60^{\circ} 00^{\prime} \mathrm{W}$

Figura 2 - Esboço geológico-tectônico da região do Encontro das Águas (modificado de Igreja \& Franzinelli 2007). Imagem original obtida no Google Earth em novembro de 2007. Q - Quaternário. Areias, siltes e argilas inconsolidadas da planície do Rio Solimões-Amazonas. K-Cretáceo Superior. Formação Alter do Chão. Arenitos e argilitos vermelhos, subordinadamente conglomeráticos, friáveis, associados a horizontes silicificados (Arenito Manaus). Lineamentos e Zonas de Falhas: 1 - Educandos, 2 - Paricatuba, 3 - Aleixo, 4 - Paciência Leste, 5 Manaquiri, 6 - Curari, 7 - Terra Nova, 8 - Marimbá, 9 - Careiro. 
INFLUÊNCIA DA NEOTECTÔNICA NA LOCALIZAÇÃO DO ENCONTRO DAS ÁGUAS A área da confluência dos rios Negro e Solimões está inserida na faixa da neotectônica transcorrente que abrange toda a parte central da Bacia Amazônica de leste para oeste (Igreja 1998). O último trecho do Rio Negro desenvolve-se ao longo de um pequeno gráben de trend estrutural N40E e N65W (Fig. 2), sendo que o último segmento do Rio Solimões apresenta a direção N40E. A confluência dos rios Negro e Solimões ocorre no cruzamento das direções estruturais N40E e N65W. Essas duas direções, junto com a direção N75E, são as que governam os lineamentos na faixa central da bacia do Amazonas. Nessa área, dão origem aos rombo-grábens Paciência, Manaus e Careiro, onde ocorre a sedimentação holocênica (Fig. 2). Essas direções também interferem na deposição sintectônica holocênica na Ilha Xiborena, que restringiu a boca do Rio Negro e definiu a amplitude do ângulo da confluência.

ASPECTOS HIDROLÓGICOS DOS RIOS O Rio Amazonas, ao entrar no Brasil na divisa com o Peru, é denominado de Solimões, e assume seu apelido a partir do Encontro das águas. O regime dos rios da Bacia Amazônica é governado pela distribuição não uniforme da pluviosidade. Na parte central da bacia a quantidade de chuvas alcança $2.500 \mathrm{~mm} /$ ano e, na bacia do Rio Negro, chega a $3.600 \mathrm{~mm} /$ ano. O canal principal que corre de oeste para leste, quase paralelo à linha do equador, desfruta de situação geográfica privilegiada, pois as estações de chuva ocorrem em tempos diferentes nos hemisférios sul e norte, o que resulta em uma situação de equilíbrio para o aporte das águas ao canal principal pelos afluentes das duas margens. Mesmo assim há diferenças do nível da água nas estações de chuva. No Rio Solimões, próximo ao Encontro das águas, esta diferença chega a $10 \mathrm{~m}$, sendo que, no Rio Negro, a mesma alcança $16 \mathrm{~m}$ (registrada no porto de Manaus). A "água branca" do Solimões deve a sua cor e o aspecto turvo aos sedimentos carregados em suspensão: argilas, siltes e areias finas (nas enchentes) em quantidades de $37 \mathrm{mg} / \mathrm{l}$ nas épocas de seca e $165 \mathrm{mg} / \mathrm{l}$ nas enchentes, de acordo com Sioli (1984). Entretanto, a grande quantidade de ácidos húmicos que provém da decomposição da matéria orgânica e os óxidos de ferro dissolvidos, confere acidez (Tab. 1) e cor marrom avermelhada às águas do Rio Negro. O gradiente do canal do Solimões, desde a confluência com o Ucajali no Peru, é de $1 \mathrm{~cm} /$ $\mathrm{km}$ na estação de seca e quase o dobro, na estação da águas altas (Sioli 1984). Apesar disso a velocidade é de $0,5-1 \mathrm{~m} / \mathrm{s}$ até $2,5 \mathrm{~m} / \mathrm{s}$ (Tab. 1). Isso é explicado pela quase ausência de atrito da grande massa de água no leito e nas margens da grande seção transversal.

A água do curso inferior do Rio Negro tem velocidade muito baixa, chegando a ser represada em algumas épocas do ano durante o pico máximo do Solimões, dando aspecto de grande lago a esse trecho do rio. A quantidade de sedimentos trazidos pelos dois rios (Tab. 1) varia muito de acordo com Forsberg et al. (1988). A causa disso resulta das diferentes condições climáticas, de relevo e de tipos de rochas nas respectivas áreas fontes. A contribuição dos sedimentos do Rio Negro em solução é proporcionalmente muito maior. Os sedimentos de fundo, de acordo com Mertes \& Meade (1985), consistem de areias finas e médias. Entretanto, Nordin et al. (1977) referem a ocorrência de areias grossas e grânulos nos sedimentos da confluência. De acordo com Sioli (1984), a temperatura da água do Solimões (Tab. 1) permanece, durante o ano, em $29 \pm 1{ }^{\circ} \mathrm{C}$, sendo mais fria que a temperatura da água do Rio Negro, que é da ordem de $30^{\circ}$ a $31^{\circ} \mathrm{C}$. Devido a essa diferença, na confluência a água do Solimões, mais fria, fica por baixo da água mais quente, tingida, porém transparente, do Rio Negro, proporcionando grandes manchas escuras na água clara e dificultando a mistura entre as duas.

RESULTADOS E DISCUSSÃO Próximo à confluência, no Rio Negro ocorre uma fossa, onde o rio alcança a profundidade de $90 \mathrm{~m}$ (Fig. 3), efeito da neotectônica local, mas, antes de entrar no Solimões, o leito do rio volta ao talvegue de $20 \mathrm{~m}$. Antes da união, o Solimões também apresenta a profundidade média em torno dos $20 \mathrm{~m}$. A abertura do ângulo da confluência dos Rios Negro e Solimões é de cerca de $90^{\circ}$. A barra da confluência, Ilha Xiborena, é constituída por bancos alongados, recurvados, os mais afastados da margem atual, os quais são os mais antigos, dispostos na direção NE/SW e os sucessivos mudando suavemente de direção até alcançar a direção atual N/S (Fig. 4). O conjunto desses bancos se apresenta com aspecto de leque, com o ápice na margem do Rio Negro e a abertura na margem do Solimões. Esta situação parece

Tabela 1 - Características hidráulicas, hidroquímicas e sedimentológicas dos rios Solimões e Negro na altura do encontro das águas.

\begin{tabular}{lcc}
\hline Variáveis & Rio Solimões & Rio Negro \\
\hline Área das bacias & $2.200 .000 \mathrm{~km}^{2}$ & $600.000 \mathrm{~km}^{2}$ \\
\hline Amplitude média & $2-5 \mathrm{~km}$ & $\begin{array}{c}\text { 3-20 km (máxima no } \\
\text { Baixo Rio Negro) }\end{array}$ \\
\hline Profundidade média & $20-35 \mathrm{~m}$ & $\begin{array}{c}20-30 \mathrm{~m}(90 \text { máxima } \\
\text { próximo ao encontro } \\
\text { das águas) }\end{array}$ \\
\hline $\begin{array}{l}\text { Descarga liquida } \\
\text { média }\end{array}$ & $100.000 \mathrm{~m}^{3} / \mathrm{s}$ & $30.000 \mathrm{~m}^{3} / \mathrm{s}$ \\
\hline ph & $6,2-7,2$ & $3,8-4,9$ \\
\hline Descarga sólida & $700 \times 10^{6} \mathrm{mt} / \mathrm{ano}$ & $6 \times 10^{6} \mathrm{mt} / \mathrm{ano}$ \\
\hline Carga dissolvida & $205 \times 10^{6} \mathrm{t} / \mathrm{ano}$ & $5,7 \times 10^{6} \mathrm{t} / \mathrm{ano}$ \\
\hline $\begin{array}{l}\text { Sedimentos de fundo } \\
\text { média e fina }\end{array}$ & $\begin{array}{c}\text { argila solta de cor } \\
\mathrm{creme}\end{array}$ \\
\hline $\begin{array}{l}\text { Velocidade da } \\
\text { corrente }\end{array}$ & $\begin{array}{l}0,5-1 \mathrm{~m} / \mathrm{s}(2-2,5 \\
\mathrm{m} / \mathrm{s} \mathrm{na} \mathrm{vazante)}\end{array}$ & $1 \mathrm{~cm} / \mathrm{s}$ \\
\hline Temperatura & $29^{\circ} \pm 1^{\circ} \mathrm{C}$ & $30^{\circ} \pm 1^{\circ} \mathrm{C}$ \\
\hline
\end{tabular}




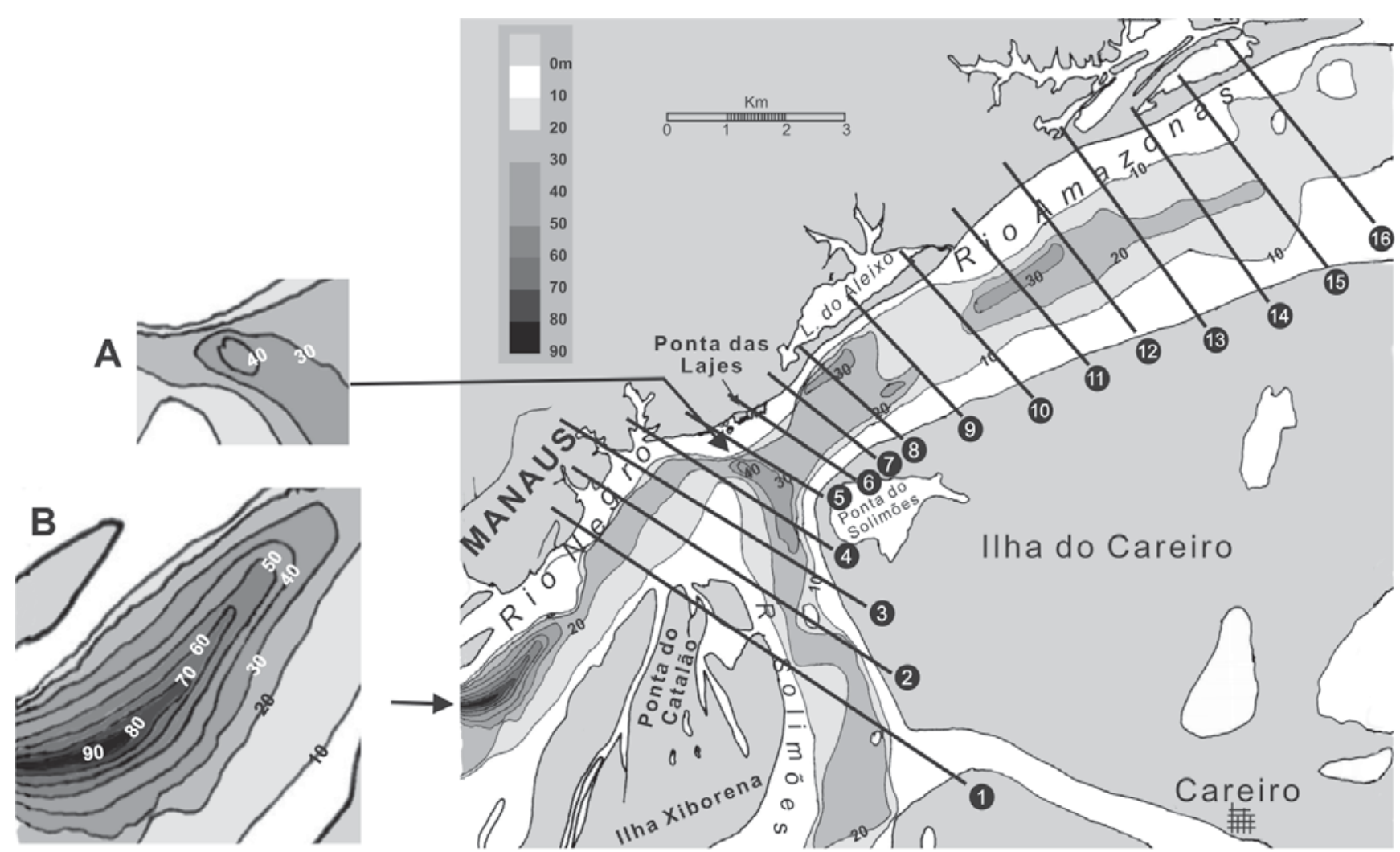

Figura 3 - Mapa batimétrico da confluência dos rios Negro e Solimões. Equidistância das curvas = $10 \mathrm{~m}$. Dados de batimetria da Carta da Marinha No 4106 B. Nos detalhes a esquerda: A - Zona do sulco erosão (scour); B Trecho do rio Negro. Marcações de 1 a 16, localização dos perfis batimétricos.

indicar mudança do ângulo da confluência, no tempo, de $15^{\circ}$ até os $90^{\circ}$ da situação atual. Aliás, remanescentes de barras curtas, com direção paralela à direção atual da barra da Ponta do Catalão, ocorrem na Ilha Xiborena, na margem do Rio Negro (Fig. 4), truncadas pelas longas barras de direção N40E, mostrando que provavelmente o ângulo da confluência teve sucessivas fases de mudanças da sua posição. Infelizmente, não se dispõem de dados cronológicos suficientes para verificar quando se deram essas mudanças, mas, sem dúvida esta situação está ligada à historia da evolução do Baixo Rio Negro no Holoceno (Latrubesse \& Franzinelli 2005) e às ações locais da neotectônica. A Ponta do Catalão, extremidade da barra da confluência, (Fig. 5 , perfis 1 e 2) apresenta mudanças consideráveis com aumento de superfície e com variação na forma, com deslocamento para SE. Isso é coerente, considerando o enorme volume de sedimentos trazidos pelo Rio Solimões e o imenso volume de água que os movimenta. $\mathrm{Na}$ frente dessa barra ocorre o sulco de erosão (scour). De acordo com Bristow et al. (1993) é uma feição desse tipo que produz a mais profunda erosão no leito do canal. A sua profundidade está relacionada à amplitude do ângulo da confluência, à largura e profundidade dos canais confluentes, à descarga total. Segundo os mesmos autores, no "scour" da confluência do Ganga com o Jamuna, ao sul de Sirajganj (Bangladesh), foi encontrada uma profundidade máxima de $30 \mathrm{~m}$, correspondente a cerca de duas ou três vezes a profundidade dos tributários, sendo que a orientação do sulco concorda com a orientação da bissetriz do ângulo da confluência, como ocorre nos modelos de canais de pequenas dimensões. Também de acordo com Parson et al. (2008), em confluências de barras anastomosadas do Rio Paraná, a profundidade do sulco de erosão alcança duas ou três vezes a profundidade média dos canais tributários, atingindo no máximo $22 \mathrm{~m}$ de profundidade e estendendo- se ao longo de $1.000 \mathrm{~m}$. Entretanto, analisando o mapa da figura $3 \mathrm{~A}$ e os perfis 3 e 4 da figura 5 nota-se que o sulco de erosão do Rio Amazonas chegou às profundidades máximas de 34 m em 1978, de 43 m em 1988 e se estabilizando em $40 \mathrm{~m}$ em 1998, correspondendo, então, a sua profundidade máxima a 1,5 a 2 vezes a profundidade média dos tributários na área do encontro. A localização do sulco mudou também no tempo, passando dos arredores da costa oeste da Ilha do Careiro (Fig. 5, perfil 4) para margem norte do Amazonas, próximo à Ponta das Lajes. A forma do sulco de erosão se apresenta irregular, de semicircular quase rodeando a Ponta do Catalão (carta de 1987) a alongada, oscilando em torno da posição da bissetriz do ângulo da confluência, alcançando $2 \mathrm{~km}$ ou mais de comprimento. Nota-se, entretanto, que no Rio Amazonas, paralelamente à margem esquerda, a partir da Ponta das Lajes, ocorre uma fossa de 40 a $31 \mathrm{~m}$ de profundidade e 3 a $4 \mathrm{~km}$ de 


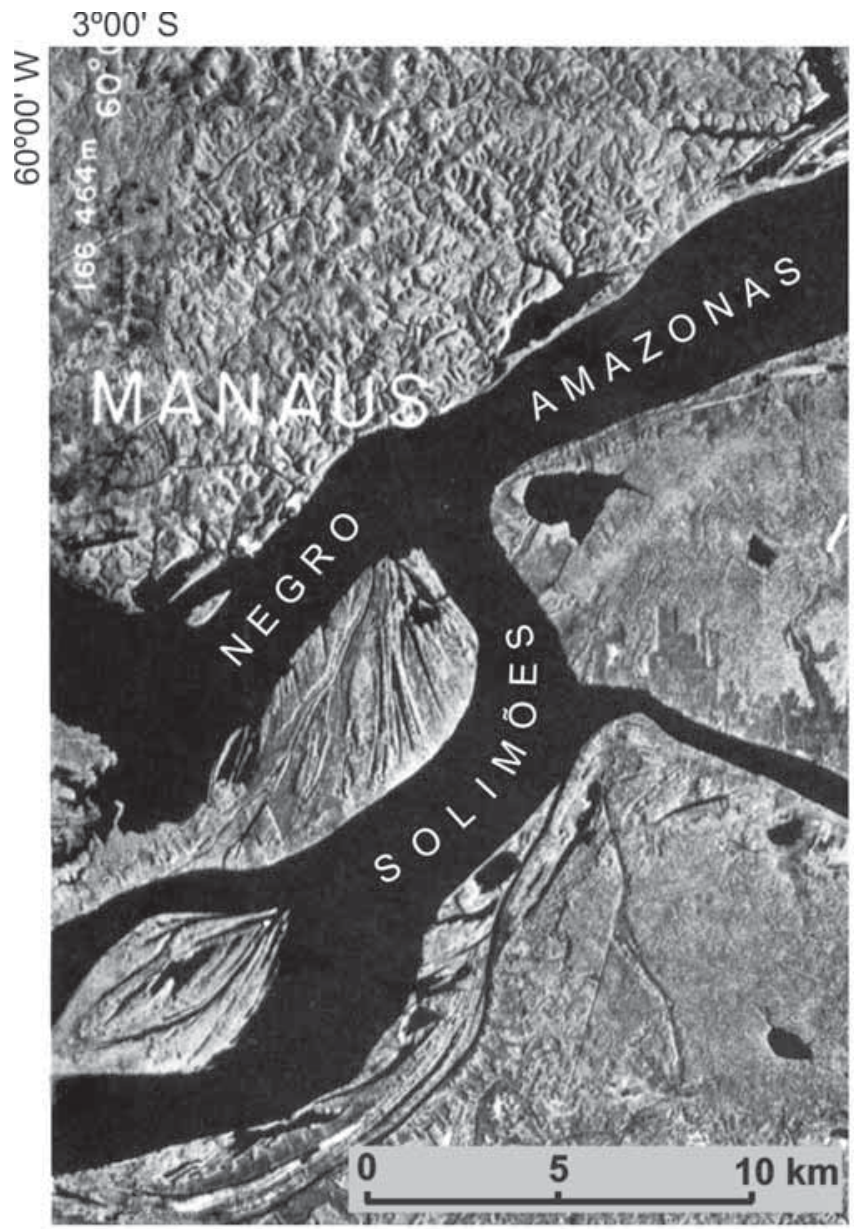

Figura 4 - Imagem do encontro das águas dos rios Negro e Solimões (início do Amazonas). O interflúvio é formado pela Ilha Xiborena, composta de bancos alongados dispostos em forma de leque com ápice na margem do Rio Negro. A barra mais longa, situada ao oeste, ocorre na direção N40E; as barras associadas sofrem rotação de cerca $70^{\circ}$ até a situação atual da Ponta do Catalão. O Paraná do Xiborena, que liga o Negro ao Solimões, ocupa a depressão da longa barra ao oeste (modificado da Folha AS-21-Y-C - Projeto Radam 1972).

comprimento (Fig. 6, perfis 5 a 9), independente do sulco de erosão, a não ser que, de acordo com dados da carta de 1988, parece que naquele período o sulco teve continuação nessa fossa. De acordo com Bristow et al. (1993) a profundidade máxima do sulco de erosão varia em condições de desequilíbrio do sistema, ou seja, quando a descarga se torna irregular. No caso do Amazonas, estas mudanças podem mostrar as variações de descargas dependentes de períodos de secas e enchentes. À jusante do sulco de erosão, o leito do Amazonas é bastante irregular. Na altura da Ponta das Lajes, o canal fica constrangido entre o afloramento de rochas silicificadas e a margem da Ilha do Careiro, possuindo a sua menor largura, mal chegando a $2 \mathrm{~km}$ (Fig. 6, perfis 6,7$)$. As barras de centro de canal, citadas na literatura como uma das características na confluência de grandes rios, ocorrem à jusante a mais de $15 \mathrm{~km}$ da Ponta do Catalão. Entretanto, ocorre uma elevação central (Fig. 6, perfis 6 a 10), contínua, com cerca de $7 \mathrm{~km}$ de comprimento, que vai se modificando, sendo mais acentuada nos perfis relativos aos anos de 1978 e 1988 (Fig. 6, perfil 9). Uma contribuição aos sedimentos que formam esta elevação deveria resultar também da ação da floculação das partículas mais finas trazidas em suspensão nas águas do Solimões pelas águas ácidas do Rio Negro. As águas não se misturam logo e a linha de divisão não é fixa, muda, se aproximando de uma ou outra margem, dependendo da preponderância de um ou outro fluxo. Na figura 2, é mostrado que os fluxos seguem separados na parte norte da Ilha do Careiro. Segundo Parson et al. (2008), a distância onde os fluxos se misturam é muito longa; por exemplo, nos rios Paraná e Paraguai parece ser de mais de $400 \mathrm{~km}$ e mais de $200 \mathrm{~km}$ em outros grandes rios. Sedimentos trazidos pelo Rio Amazonas são depositados e retrabalhados na margem norte da Ilha do Careiro e dispostos em barras laterais, por acreção lateral. Na margem esquerda, em seguida à Ponta das Lajes, onde a Formação Alter do Chão se afasta no sentido NE, ocorre deposição de sedimentos formando restinga, que separa o Lago do Aleixo do Rio Amazonas (Fig. 6, perfil 10). À jusante o canal do Amazonas vai se ampliando e a profundidade diminuindo, chegando a $20 \mathrm{~m}$ (Fig. 7, perfis 14,15 e 16$)$.

CONCLUSÕES Apesar dos modestos recursos disponíveis para desenvolver o estudo preliminar do leito do Rio Amazonas e investigar os fenômenos que ocorrem no encontro dos seus dois grandes formadores, alguns resultados interessantes foram obtidos. No leito dos confluentes, antes do encontro, não ocorre a queda tipo avalanche, que é comum nos canais de pequeno tamanho e nos modelos de simulações de laboratório. Essa feição não é encontrada nos raros exemplos de grandes rios, isto é, nos rios Jamura e Ganga (Bangladesh) e no Paraná. A área da Ilha Xiborena e Ponta do Catalão é a que mostra as maiores mudanças no período de 1978 a 1998, com sequências rápidas de erosão e deposição, que são mostradas nos perfis da figura 5 . As modificações do local do sulco de erosão indicam que, para o Rio Amazonas, o elemento mais importante para o desenvolvimento dessa feição não é o valor da abertura do ângulo da confluência, mas, sim, o fluxo da carga total. As profundidades máximas detectadas para o sulco de erosão, 40 e 43 m, correspondem a cerca de 1,5 vezes a profundidade média dos tributários. Esse valor é compatível com os dados obtidos em outros estudos de grandes rios. As variações dos valores da profundidade do sulco de erosão são devidas a irregularidades na descarga, que, por sua vez, mostra condições de desequilíbrio no sistema. Na Bacia do Solimões, esse desequilíbrio pode ser causado por aporte anormal de sedimentos que reflete a erosão dos solos desmatados na bacia. 

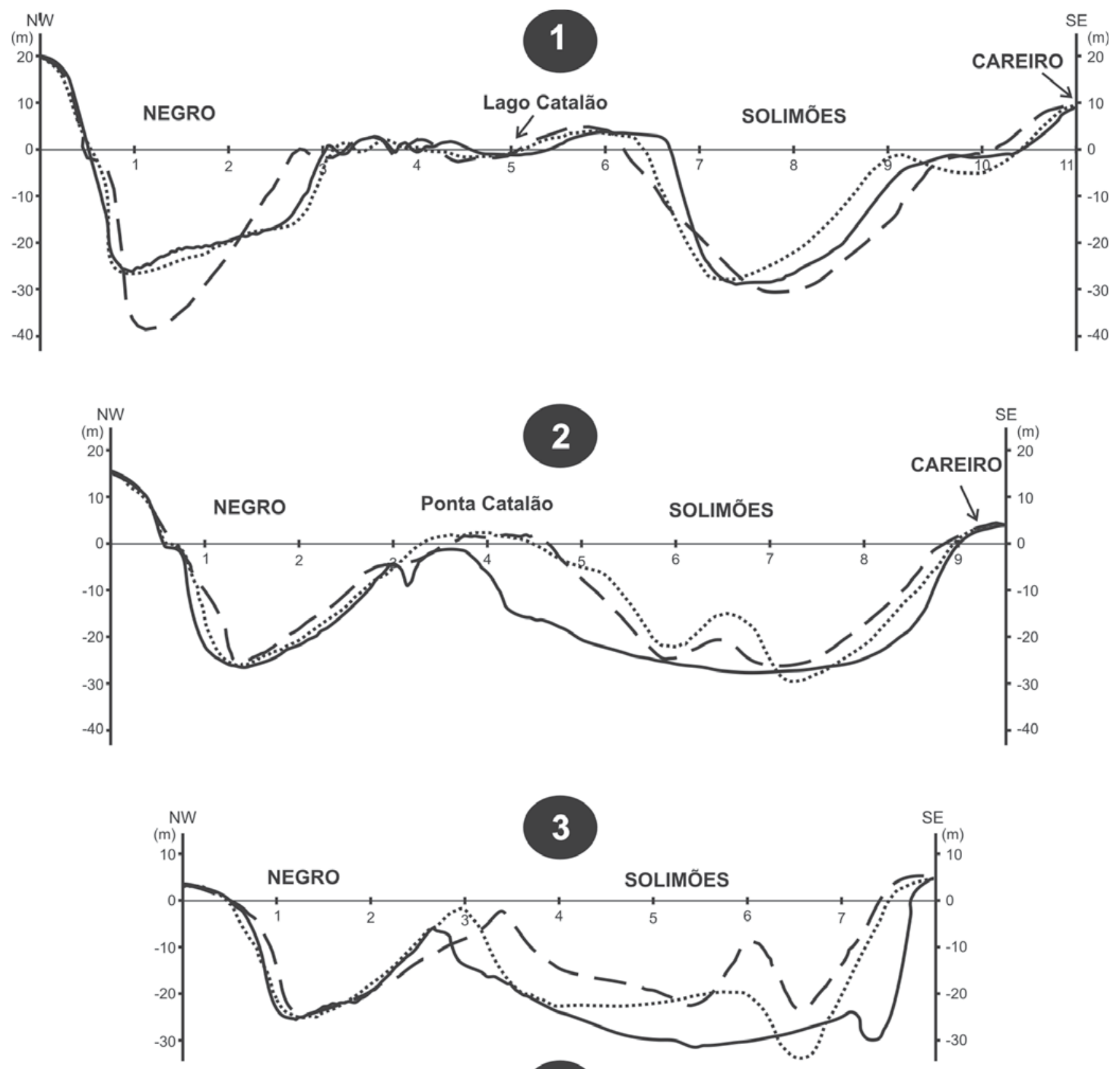

4
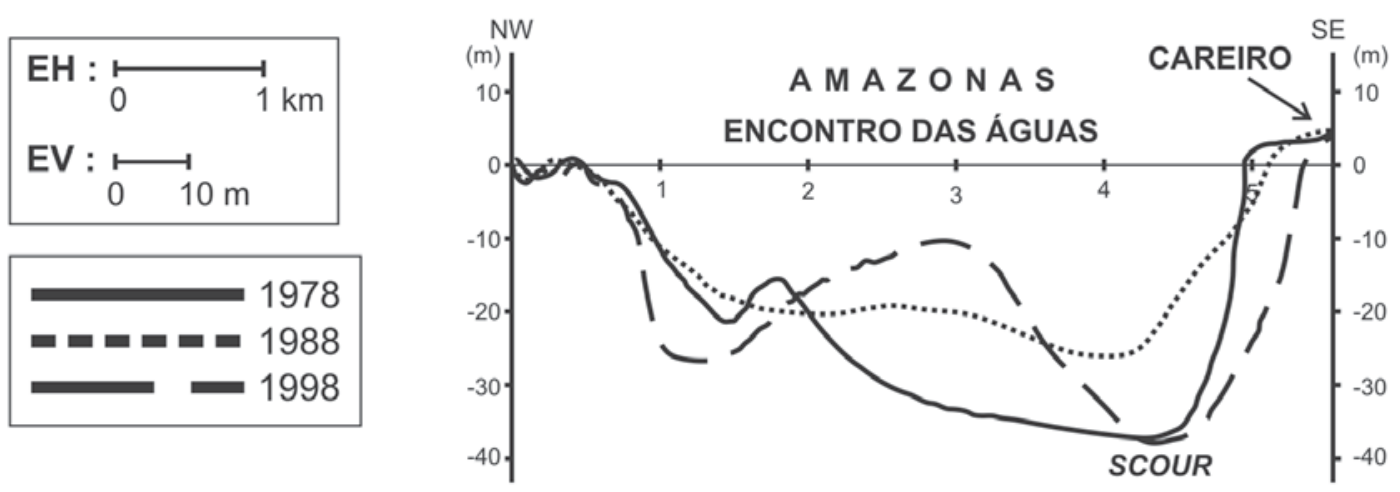

Figura 5 - Perfis batimétricos do encontro das águas. 
5

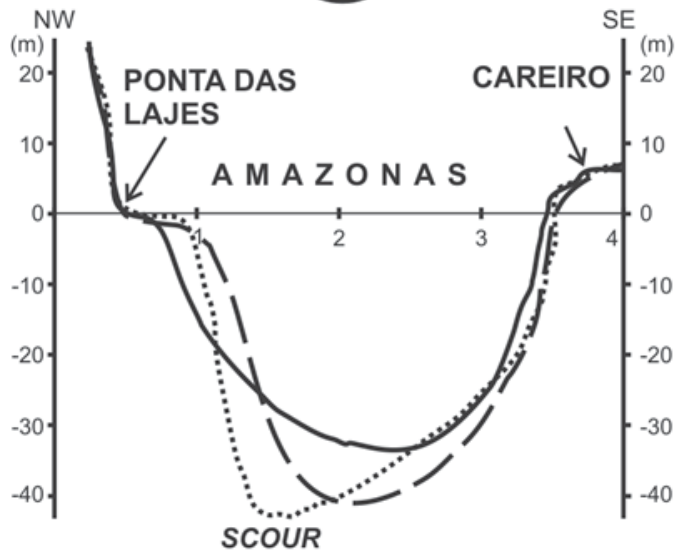

7

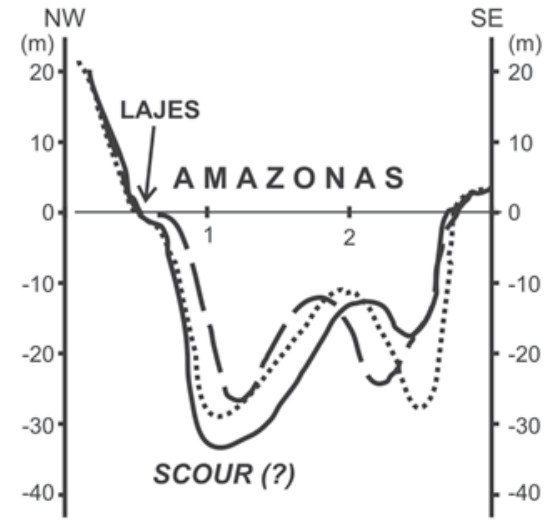

9
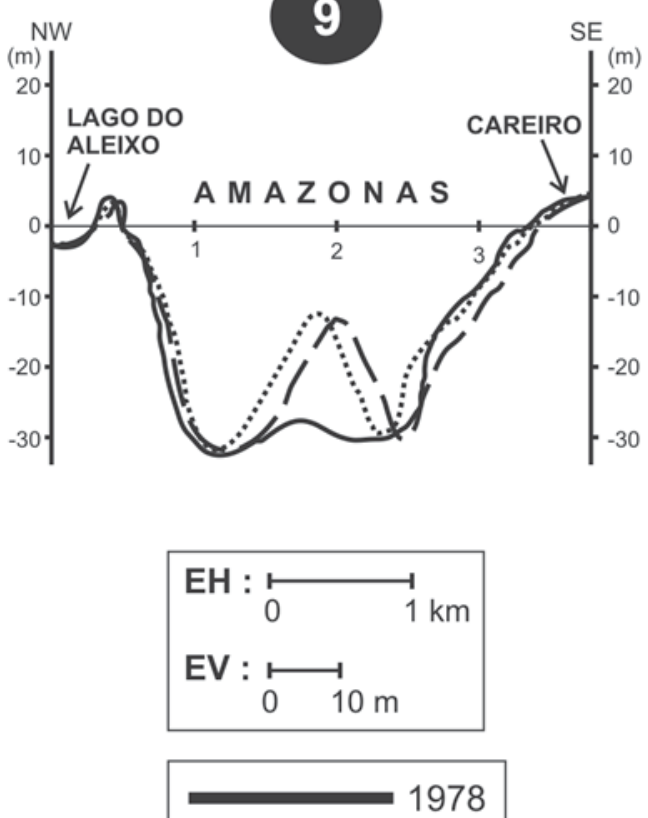

$=\square= \pm=1988$

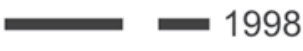

6

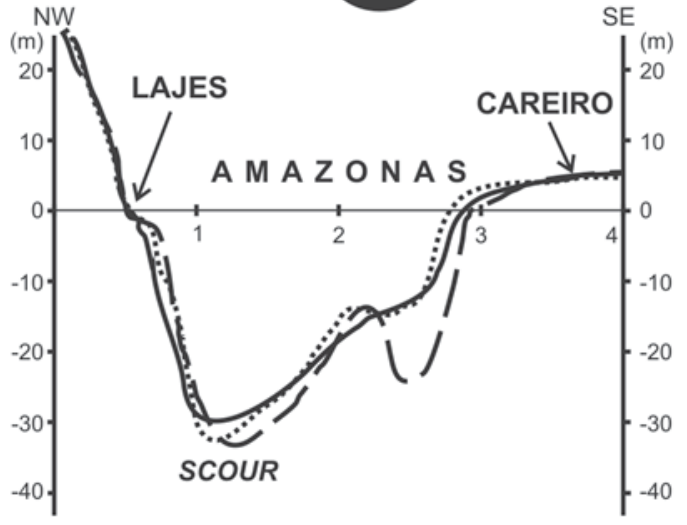

8

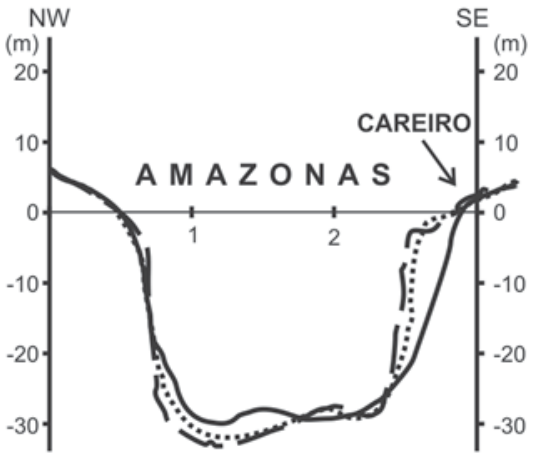

10

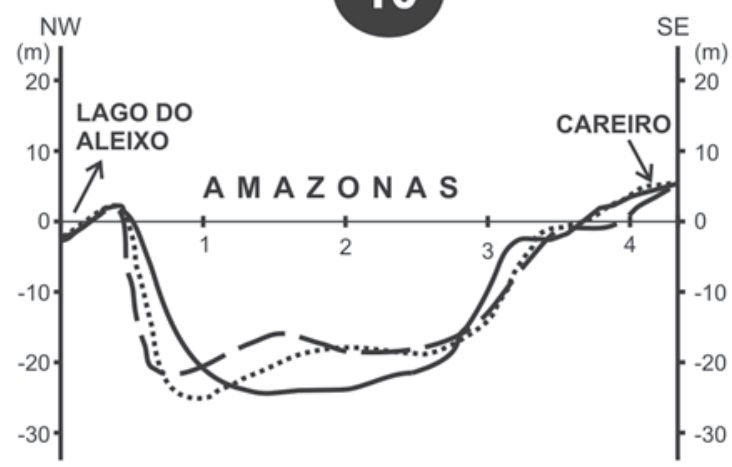

11

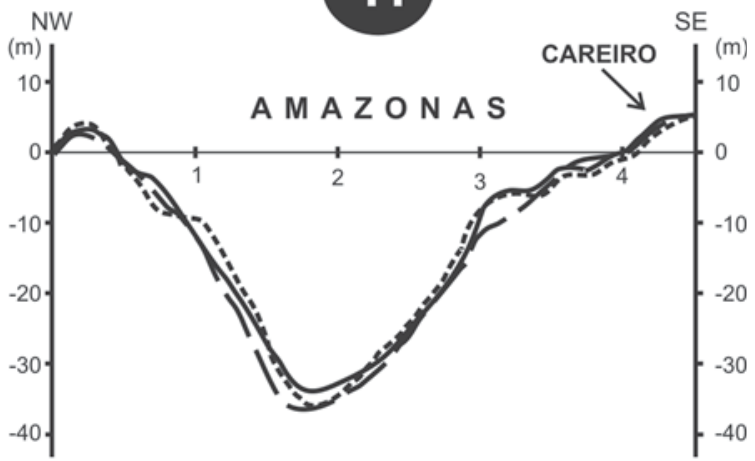

Figura 6 - Perfis batimétricos do Rio Amazonas. 

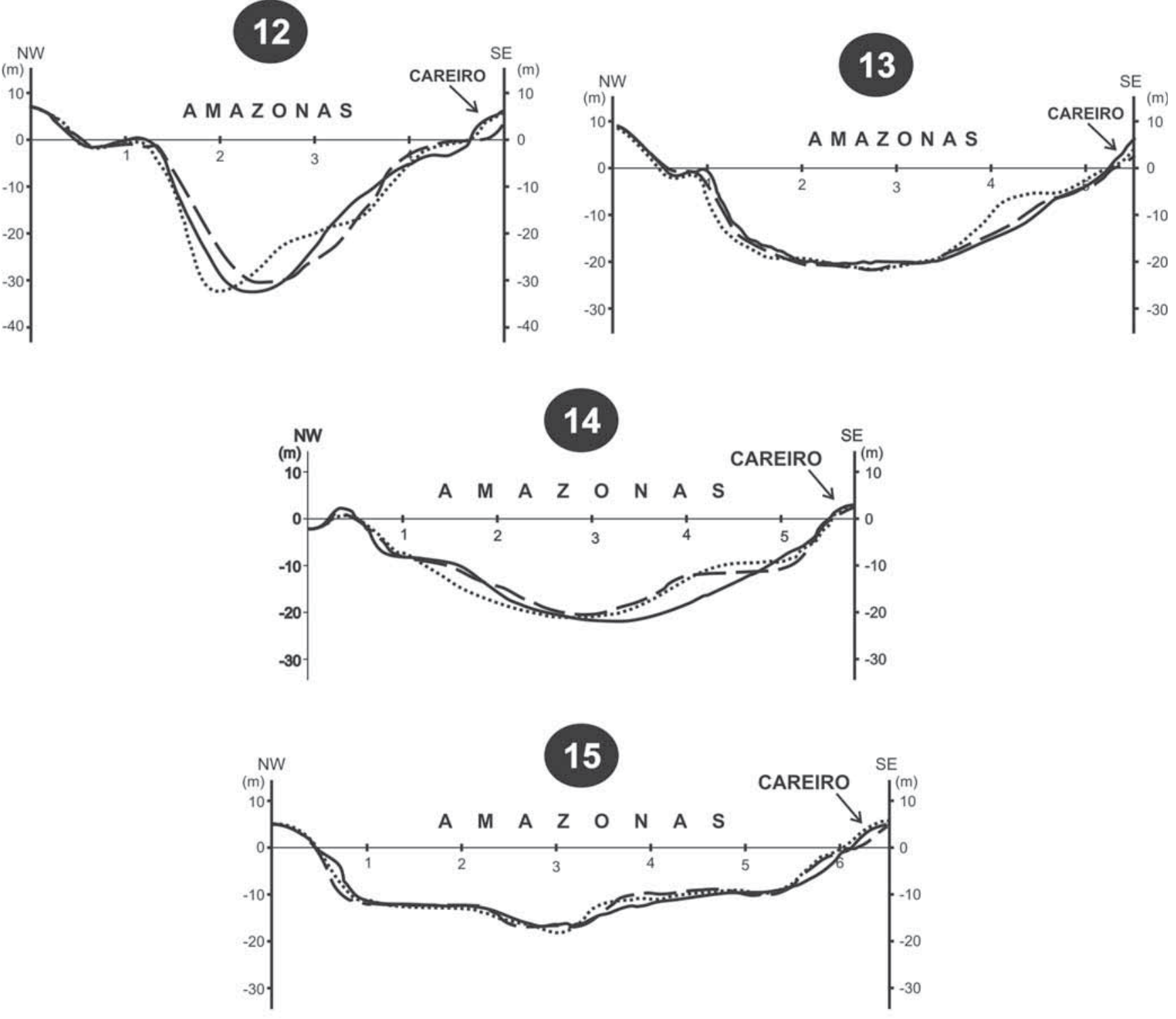

\section{6}
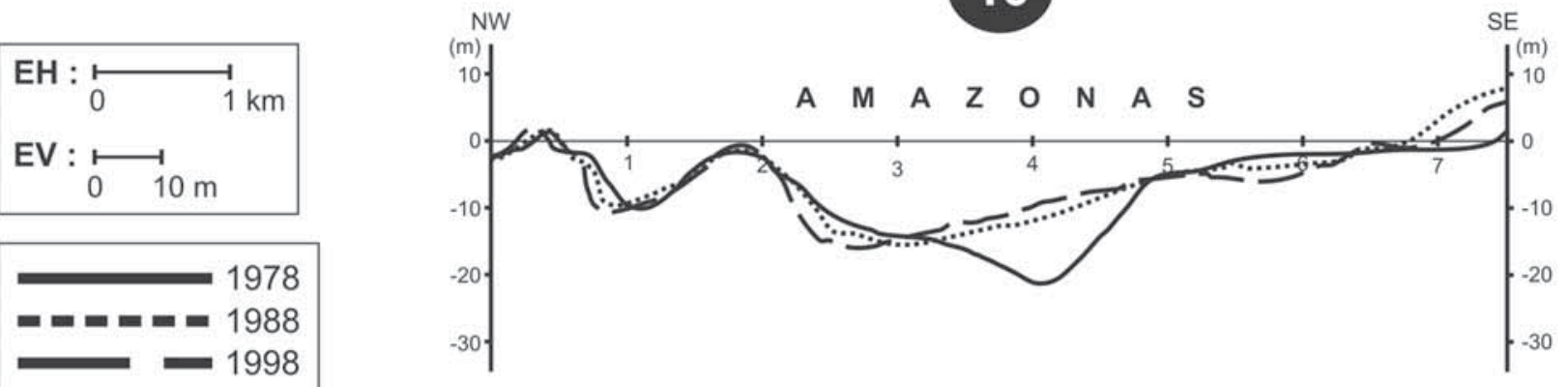

Figura 7 - Perfis batimétricos do Rio Amazonas.

Agradecimentos Ao Dr. Oscar Orfeo, do Centro da Ecologia Aplicada Del Litoral (CECOAL) e Consejo Nacional de Investigaciones Cientificas y Tecnicas (CONICET), Argentina, pelas bibliografias de confluências de grandes rios; ao Prof. José Candido Stevaux da Universidade
Estadual de Maringá (UEM), pelo estímulo para a elaboração deste artigo; ao colega Prof. Hailton Igreja, pelo constante acompanhamento nos trabalhos de neotectônica; ao Msc. Daniel Ribeiro Fernandes, pelo incansável auxílio no layout e confecção das figuras do artigo. 


\section{Referências}

Albuquerque R.O. 1922. Reconhecimento geológico do Vale do Amazonas. Rio de Janeiro, Serv. Geol. Mineral. Bras., $84 \mathrm{p}$.

Bates H.W. 1864. The Naturalist on the river Amazons. Berkeley, Univ. California Press, $465 \mathrm{p}$.

Best J.L. 1988. Sediment transport and bed morphology at river channel confluences. Sedimentology, 35:481-498.

Best J.L. \& Ashworth P. 1997. Scour in large braided rivers and the recognition of sequence stratigraphic boundaries. Nature, 387:275-277.

Bristow C.S., Best J.L., Roy A.G. 1993. Morphology and facies models of channel confluences. Spec. Publs Int. Ass. Sediment, 17:91-100.

Forsberg B.R., Martinelli L.A., Meade R., Richey J.E. 1988. Sediment delivery rates for the Amazon River and its principal Brazilian tributaries. In: AGU, Chapman Conference, 1, Anais, p. 77-81.

Franzinelli E. \& Igreja, H. 2002. Modern Sedimentation in the Lower Negro River, Amazonas State, Brazil. Geomorph., 44(3-4):241-259.

Franzinelli E. \& Potter P.E. 1983. Petrology, chemistry and texture of modern river sands, Amazon River system. $J$. Geol., 91:23-39.

Gibbs R.J. 1967. The Geochemistry of the Amazon River system: part 1: The factors that control the salinity and composition and concentration of suspended loads. Geol. Soc. Amer. Bull., 78:1203-1232.

Igreja H.L.S. 1998. Aspectos do modelo neotectônico da Placa sul-americana na Província estrutural amazônica, Brasil. Tese Concurso Prof. Titular, Universidade Federal do Amazonas, Manaus, 155 p.

Igreja L.H., Franzinelli E. 2007. Aspectos da Neotectônica no fenômeno do "Encontro das Águas", Cidade de Manaus, AM. In: Simp. Geol. da Am., 10, Anais, 1 CD-Rom.

Latrubesse E.M., Franzinelli E. 2005. The late Quaternary evolution of the Negro River, Amazon, Brazil: Implications for island and floodplain formation in large anabranching tropical system. Geomorph., 70:372-397.

Marinha do Brasil. 1978-1988-1998. Hidrografia e Navegação. Manaus, cartas de praticagem de Manaus a Tabatinga, No 4106 B.
Mertes L.A.K. \& Meade R.H. 1985. Particle sizes of sands collected from the bed of the Amazon River and its tributaries in Brazil during 1982-84. Washington, U.S. Geological Survey, Open-File Report 85-333, 20 p.

Morisawa M. 1968. Streams their dynamics and morphology. New York, McGraw-Hill Book Company, 175 p.

Nordin C.F., Meade R.H., Mahoney H.A., Delaney B.M. 1977. Particle size of sediments collected from the bed of the Amazon River and its tributaries in june and july 1976. Washington, U.S. Geological Survey, Open-File Report 77-400, 19 p.

Oltman R.E. 1967. Reconnaissance investigations of the discharge and water quality of the Amazon. In: Simp. sobre Biota Amazônica, 3, Ata, p. 163-185.

Parson D.R., Best J.L., Lane S.N., Kostaschuk R.A., Hardy R.J., Orfeo O., Amsler M.L., Szupiany N. 2008. Large river channel confluences. In: Rice S., Roy A., Rhoads B. (eds.) River Confluences, Tributaries and Fluvial Network. New Jersey, John Wiley and Sons Ltd., 474 p.

Potter P.E., Franzinelli E. 1985. Fraction analyses of modern river sand of Rio Negro and Solimões, Brazil, Implications for the origin of quartz-rich sandstones. Rev. Bras. Geoc., 15(1):31-35.

Projeto Radam. 1972. Mosaico semi-controlado de Radar Folha SA-21-Y-C. Brasília, Dep. Nac. Prod. Miner. MME, imagens de radar.

Sioli H. 1991. Amazônia Fundamentos da ecologia da maior região de florestas tropicais. 3.ed., Petrópolis, Edit. Vozes, $72 \mathrm{p}$.

Sioli H. 1984. The Amazon. Limnology and landscape ecology of mighty tropical river and its basin. Dordrecht, Pub. Junk, 800 p.

Stallard R.F., Edmond J.M. 1983. Geochemistry of the Amazon 2: The influence of the geology and weathering environment on the dissolved load. J. Geophys. Res., 88:9671-9688.
Manuscrito ID 17886

Submetido em 30 de junho de 2010 Aceito em 21 de dezembro de 2011 